turbance until the second night after the operation, when the patient had several rigors. At 10 A.M. temperature was $103^{\circ} \mathrm{F}$. On the dressing being removed $x$ quantity of fetid pus, but of a laudable colour, escaped. On examination with the speculum this discharge was seen welling from the uterus, the os being dilated to the size of a threepenny piece, the parts being swollen. The vagina also participated in the general inflammatory action. The glands in both groins were enlarged and very tender on pressure. Instead of the ordinary dressing a speculum was now introduced and fixed, filled tightly with carbolic tow, so that the discharge might escape. Five grains of quinine, with ten drops of sedative solution of opium, were administered every four hours.

The inflammatory fever lasted for four days, the temperature, mornings and evenings, varying from $100^{\circ}$ to $102^{\circ}$. The secretion now became of an albuminoid nature, which soon ceased with a subsidence of the irritative fever and swelling of the inguinal glands.

Before leaving the hospital, about three weeks after the operation, a normal menstrual flow took place.

The case was entirely lost sight of until April 29th this year, when on a journey into the country Mr. Leeming met her medical attendant, who informed him that the patient had been delivered of a full-grown female child after a natural labour, three days previously. Mr. Leeming visited her, when her expression of countenance, instead of being dull and half idiotic as previous to the operation, was bright and intelligent, and she said that after she left the hospital she was quite a different woman, and had never been so well.

\section{TOTARA DISTRICT HOSPITAL, ROSS, NEW ZEALAND.}

HYDATIDS OF LIVER; ASCITES; MULTIPLE ABSCESSES; DEATH.

(Under the care of Dr. R. H. BAKEwELL.)

J. B-, an Englishman aged forty-two, a miner, was admitted June 17th, 1878. This patient was in the hospital when Dr. Bakewell took charge in October, 1878. He was then suffering from black jaundice, the tint of the skin being that of a very dark mulatto. He was much emaciated and very weak. The urine was very dark from bile; the fæces were clay-coloured. The liver-edge could be felt at the level of the iliac crest on the right side, while the left lobe formed a prominent and conspicuous smooth and rounded tumour about three fingers' bread th below the unbilicus. He had previously been tapped several times for ascites, and the girth of the abdomen taken at the umbilicus was now 421 inches. The respiration was short and difficult, and although he had been tapped only a fortnight before, he pressed for a repetition of the operation. His legs were anasarcous and very tense. On Oct. 3rd he was tapped. The quantity of fluid was not exactly measured, but it filled about three-fourths of an ordinary iron bucket. To take five grains of iodide of potassium three times a day; and to have iodine liniment applied over the region of the liver.

On Oct. 16th he had very much improved. The girth round the umbilicus was 37 inches, mostly caused by flatus, from which he suffered very much. Acupuneture of the legs had been performed on the preceding day. The dulness on the richt side was increasing upwards, and was now complete up to an inch below the spine of the scapula; no respiratory sound could be heard in the lower half of the right lung posteriorly. There were friction-sounds and some pain; respiration was puerile in the upper half and on the left side. Distance from left nipple to umbilicus $12 \frac{1}{8}$ inches; from right nipple to umbilicus, $12 \frac{7}{8}$ inches ; semi-circumference of chest, right side $17 \frac{1}{4}$ inches, left side $16 \frac{7}{8}$ inches.

On the 28th, the left lobe of liver was punctured with a fine trocar; nothing came away but turbid reddish serum, which contained blood and liver cells; very little pain was caused. At this time, owing to the marked prominence of the left lobe, there was a suspicion of cancer. Nothing like cancer-cells could be discovered. A copious pustular eruption appeared on the face. The iodide of potassium was omitted. A few days after, the eruption having disappeared, a smaller dose of the iodide of potassium, together with twenty minims of syrup of the iodide of iron, were given three times a day. Meanwhile there was no furtber accumulation of fluid in abdomen or legs.
On Nov. 2nd, the measurements were, from umbilicus to right nipple, 12 inches; to left, 115 iuches; semi-circumference same as on Oct. 16th ; greatest girth of abdomen, 40 inches. On Dec. 2nd, measurements from right nipple to mirl-sternum, $3 \frac{7}{8}$ inches ; from left, $3 \frac{1}{2}$; from umbilicus to both nipples, $12 \frac{1}{4}$ inches; abdominal measurement as last month. To take five grains mercury pill daily. On Jan. 2nd, 1879 , the circumference of the abdomen was 40 inches ; from umbilicus to right nipple, $11 \frac{3}{4}$ inches; to left, $11 \frac{5}{8}$ inches. On Feb. 2nd, abdominal circumference was $41 \frac{1}{8}$ inches ; from nipples to umbilicus, 12 inches. Some enlargement and tenderness of mammary glands.

At this time the enlargement was clearly owing to the gradual growth of the liver, and not to the accumulation of fluid in the peritoneum. The wasting and emaciation were so extreme that it was thonght advisable to discontinue the iodine. Small doses of dilute nitro-muriatic acid in quassia were given instead, and the nitro-muriatic acid sponge-bath employed.

Up to March 7 th he had been taking a large quantity of milk daily; this was diminished. Early in the morning of this day (about 3 A.M.) sudden and severe rigors occurred, with vomiting and pain in tumour. Temperature at night $104^{\circ}$. On the 11th the pain under the right scapula was severe. Cough was very troublesome. There was no expectoration, nor any moist sounds. The tumour was rapidly increasing, and the emaciation was very great. Acupuncture was occasionally practised in legs to relieve tension, but there had been no accumulation of fluid in peritoneum since October. On the 12th fluctuation was well marked in the right eleventh costal interspace. This was explored with a hypodermic syringe, and clear fluid was withdrawn. The spot was then tapped, and about three ounces were taken; no more could be obtained, though the trocar was driven well home. That day and the next rigors occurred, and two or three more exploratory punctures were made, but the abscess could not be reached, and nothing but hydatid fluid was removed. On the morning of the 13 th the surgeonsuperintendent was called up by the night wateher in the belief that the man was dying. Respiration was very rapid and shallow, the pulse small, feeble, and rapid, and the patient presented a most ghastly spectacle. His colour was darker than ever, and he was emaciated to the last degree. Nevertheless he still persisted in saying that he should get well, and that if he could get rid of the swelling he should be all right. With the exception of this delusion his mind was clear almost to the last, but about $8 \mathrm{~A}, \mathrm{M}$, on the morning of the 14th he became semi-comatose, and died two hours afterwards.

Necropsy, made about four hours after death.-Weather very hot. Nosigns of decomposition. Hypostatic congestion of all the lower parts of the body. Skin of an intense yellow colour, verging upon brown. On opening the abdomen the liver was found to form an immense tumour overlying most of the abdominal viscera. An incision was made into the left lobe, and some pints of pus came away. Another abscess was opened before the liver was removed, and also a large hydatid mother-cyst in the right lobe. With some diffculty the liver was removed, but this could not be done without opening another hydatid cyst. It was then weighed, with most of the loose hydatids, of which there were hundreds, varying in size from that of an orange to less than that of a pea. It then weighed $16 \frac{1}{4} \mathrm{lb}$. It was thought that if the liver had been removed without opening the abscess and cysts, it would have weighed at least $20 \mathrm{lb}$. The kidneys were deeply stained with bile, but were otherwise healthy. The right lung was much compressed, and in a state of red hepatisation. The left was emphysematous, but otherwise healthy. The other organs presented nothing worthy of particular notice. The brain was not examined.

Remarks by Dr. BAKEWELL. - This case was somewhat remarkable on account of the enormous development of hydatids without their having caused perforation of the diaphragm, or any part of the peritoneal investment of the liver. Hydatid tumours of the liver are exceedingly common in these colonies, but usually long before they attain the size they did in this case they perforate the liver, and are discharged through the lung, or an abscess is formed which breaks into the bowel. Those cases are the commonest in which the diaphragm is perforated. In such the disease, though long and tedious, is often cured. In one instance which came under my care in private practice the patient had been spitting up hydatids from the lungs for eighteen months. The symptoms all ceased after the continuous use 
of a decoction of the tree-ferm root for six weeks. It is noteworthy that there was no trouble from ascites after iodine had been employed exterually and internally, although the growth of the tumour was only for a time arrested.

The diagnosis of hydatids of the liver is often attended with much difficulty. The presence or absence of the hydatid fremitus on percussion depends on the greater or less depth of the hydatid in that portion of the liver which is percussed. Hydatid fremitus was not observed in $J$. B - 's case until a ferr days before death, and then an exploratory puncture proved that a hydatid cyst was situated immediately beneath the walls of the chest, with notluing but a thinned diaphragm between it and the intercostal muscles.

HYDATIDS OF RIGHT LUNG ; OBSTINATE DRY COUGH ; FORMATION OF WHITE FIBRINOUS CLOT IN HEART; DEATH.

J. M. S_, a Swede, male, aged fifty-three, a gold miner, was admitted Dec. 4th, 1878 . On admission he complained chiefly of internal homorrhoids, which bled a good deal. He was a fair-complexioned man, of highly nervous temperament, had led a solitary life, being what is called amongst miners a "halter"-that is, working by himself. He had been very unfortunate, and was very silent and reserved. He complained of a troublesome cough. An examination of the chest was carefully made, and repeated daily after admission for some time. Nothing could be detected except a small patch somewhat dull, situated posteriorly on the right side, just below the spine of the scapula. The patch was of an oval shape, and not larger than the longitudinal section of a walnut. Breathing was coarser over this spot, and local resonance was slightly increased. The uvula was elongated, and as it was thought that this might have something to do with the cougb, a gargle of capsicum and tannin was ordered, together with some compound tincture of camphor and sulphuric acid.

On Dec. 9th, the congh being still troublesome, a small blister was applied to the right side. On the 12th the cough was still troublesome. Sputa very slight, but just tinged with blood. Ordered four ounces of wine daily, twenty minims of tincture of belladonna thrice daily, and to continue the gargle. On the 16 th the cough was as bad as ever, and disturbed the other patients. There was no change in the lung. It was found that when his attention was drawn off the cough ceased for a time. On Dec. 22 nd the dulness had extended greatly; there was no notable hremoptrsis, but the sputa were white, and occasionally tinged. On the 2sth considerable hremoptysis occurred, and the dulness was rapidly increasing. From this time until his death varions remedies were tried to allay the cough, but all of them afforded only temporary relief. He had porter, milk, cod-liver oil, and good meat diet, but still he continued to grow weaker and thinner. On January 20 th the breath had an extremely offensive odour, suggesting gangrene of the lung. The right chest measured one inch more than the left in line of nipples. There was considerable oedema in the right lumbar region; none in the left. On the $23 \mathrm{rd}$ there was dulness with complete absence of respiratory murmur over the right chest posteriorly from the spine of scapula. The dulness was bounded by the posterior wall of axilla. Fetor of breath persisted.

Though the man was obviously growing weaker, there was nothing to indicate any immediate danger, or to require any particular watchfulness at night. On the night of the 25th he was seen by the surgeon-superintendent as usual. On the morning of the 26 th he was found sitting up in his usual posture, quite dead. One of the patients in an adjoining ward had heard him coughing until about 1 A.M., but no sound was made that led him to suspect anything extraordinary.

Necropsy. - A hydatid cyst was found occupying the lower half of the right lung. The walls ot the cyst were in part gangrenous. The contents were a number of hydatids and foul-smelling pus, mixed with fluid. The liver was healthy. The right auricle and ventricle were filled up with white fibrinous clots. Nothing else noteworthy was observed.

Remarks. - Although the symptoms on admission were ambiguous, and the physical signs obscure, yet the persistency of the cough, coupled with the existence of a small but well-defined patch of dulness in the posterior part of the right lung, just below the spine of the scapula, suggested a hydatid tumour. For some time it was doubtful whether it might be that or a nodule of cancer, or possibly lobular pneumonia undergoing caseous decreneration, but the com parative rarity of either of these two diseases, and the frequency of hydatids, rendered the hypothesis of hydatid disease the more probable. In view of the increased dulness the hemoptysis, the fetid breath, without any of the physical signs of a cavity, or of pneumothorax, the diagnosis was ren dered all but certain. Dr. Bakewell was about to aspirate the dull part of the chest, to remore the flujd, and had determined to do so on the very day the patient died. Fortunately the operation was not performed.

A third case of hydatids of the lung and liver was admitted in a moribund state, but as the friends would not allow a post-mortem it is not worth while to record the symptoms.

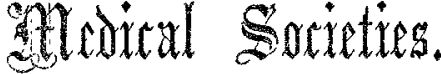

\section{ROYAL MEDICAL \& CHIRURGICAL SOCIETY.}

\section{Basic Carity of the Lung treated by Paracentesis.}

THE concluding meeting of this Saciety for the session was held on the 8 th ult, J. E. Erichsen, Esq., F.R.S., President, in the chair. Only one paper was read and discussed. It dealt with the comparatively novel subject of the operation of paracentesis of pulmonary cavities, and was contributed by Dr. R. Douglas Powell and Mr. R. W. Lyell. The case recorded was one of basic cavity following on pneumonia, and complicated with bronchicctasis. The operation afforded remarkable relief for some weeks, when the expectoration again became fetid, and death ensued from an attack of pleuro-pneumonia of the opposite lung. The paper discussed at length the indications for the operation, and reviewed the cases hitherto published.

The following is an abstract of the paper on a case of Basic Cavity of the Lung treated by Paracentesis, by Dr. R. Dovglas PowELL and Mr. R. W. LyELL. The case related was that of a man aged forty-nine, of previous good health but intemperate habits, who, in December, 1878, had had bronchitis, followed, in the ensuing February, by pleuropneumonia and fetid expectoration. He improved after a time, but relapsed again in July, and in August was admitted into the Middlesex Hospital under Dr. Powell's care. On admission the physical signs showed consolidation of the lower lobe of the right lung, with excavation of its central portion, the cavity signs being centred about the level of the seventh dorsal spine in the line of the angle of the scapula. There was considerable hectic, diarrhœe, and anorexia. The breath and expectoration were extremely fetid, the latter being muco-purulent in character, and very abundant, amounting to about one pint in the twenty-four hours. The area of excavation having been carefully. marked out, the operation of paracentesis was performed by Mr. Lyell on Sept. 11th. A medium-sized aspiration-trocar was first thrust in at the eighth space mid-scapular line, and a free incision having been made through the tissues down to the intercostal membrane, the fine trocar was withdrawn, and a full-sized hydrocele trocar inserted, which, after slightly enlarging the opening; was in its turn removed, and a large drainage-tube introduced. Carbolised dressings were applied. A moderate quantity of secretion escaped from the wound (which gave rise to no serious bleeding), and the discharge subsequently from the tube, although free, was never abundant. The expectoration and cough, however, at once almost entirely ceased. The wound was dressed daily under the carbolic spray with the view of disinfecting it and the cavity, and injections of Condy's solution were used. On October the 2nd there was some return of fetor of breath, that of the discharge from the tube having never quite been corrected. Some trouble was occasioned by the tube slipping out, its reintroduction being hindered by encroaching granulations, and the tube was felt to strike against some impediment deep in the lung. The channel was kept dilated, however, and the patient improved in strength, and on the 20th was transferred to the Brompton Hospital. Fetor of sputa returned towards the end of the month, however; although the amount expecto- 